\title{
Portuguese Position Paper on the Use of Biosimilars in Psoriasis
}

\section{Position Paper Português Sobre o Uso de Biossimilares na Psoríase}

Tiago TORRES $\square^{1,2}$, Ana FERREIRA ${ }^{3,4}$, Paulo FERREIRA ${ }^{5}$, Martinha HENRIQUES ${ }^{6}$, Luiz LEITE ${ }^{7}$, Sofia MAGINA ${ }^{8,9}$, Gabriela MARQUES PINTO ${ }^{10}$, Hugo OLIVEIRA ${ }^{11}$, Artur SOUSA BASTO ${ }^{12}$, Rui Tavares BELLO ${ }^{13}$, Paulo VARELA ${ }^{14,15}$, António MASSA ${ }^{16}$, Manuela SELORES ${ }^{2,17,18}$, Paulo FILIPE ${ }^{19,20,21}$; On behalf of the Portuguese College of Dermatology and the Portuguese Society of Dermatology and Venereology Acta Med Port 2016 Sep;29(9):574-577 - http://dx.doi.org/10.20344/amp.8118

Keywords: Biological Agents; Biosimilar Pharmaceuticals; Portugal; Psoriasis/drug therapy.

Palavras-chave: Agentes Biológicos; Medicamentos Biossimilares; Portugal; Psoríase/tratamento.

The advent of biologic agents revolutionized the treatment of psoriasis and psoriatic arthritis, providing treatment option to many patients previously unresponsive to phototherapy and conventional systemic treatments. ${ }^{1}$ The unprecedented impact on these patients has been major, with significant overall sustained positive effects on disease burden, quality of life issues as well on systemic inflammation and comorbidities. Likewise, their benefit/risk ratio has proved excellent provided that the recommended pre-inclusion measures and follow-up are thoroughly respected. ${ }^{2}$ However, these therapies impose a heavy burden on the healthcare system due to their high costs. In 2013 , a total of $27 \%$ of pharmaceutical sales were biological agents, mainly for cancer and immune-mediated diseases, and in 2015, two of the five top selling therapies were TNF- $\alpha$ inhibitors, adalimumab and etanercept. ${ }^{3}$

Biosimilars, defined by EMA as a 'biological medicinal product that contains a version of the active substance of an already authorised original biological medicinal product (reference product) ${ }^{\prime 4}$ are an attractive strategy to reduce therapy-related costs and increase patient access to highly effective drugs. As innovator biologics used to treat psoriasis and psoriatic arthritis are losing patent protection, there are several biosimilars versions of those agents being developed. ${ }^{5}$ Biosimilars must be viewed differently than generic copies of chemically synthetized drugs, due to their high molecular weight, complex molecular structure and post-transcriptional modifications, such as glycosylation, methylation, oxidation and deamination, that impact on tertiary and quaternary structure. In order to be approved by regulatory agencies, biosimilars must prove to be highly structurally analogous to the reference drug and to be highly similar in terms of quality, safety, efficacy and immunogenicity profile to the originator agent. ${ }^{6}$ Thus, as their name indicates, biosimilars are highly similar to the originator product, but due to differences in manufacturing processes they are not identical.

Biosimilars may cost $25 \%-30 \%$ less than the original agents, as the manufacturing process and development costs are considerably lower. Moreover, through market pressure, biosimilars may also reduce the costs of the original biopharmaceuticals. Thus, biosimilars are expected to reduce health care costs and to increase patient access to biologic agents, contributing to the financial sustainability

1. Consulta de Psoríase. Serviço de Dermatologia. Centro Hospitalar do Porto. Porto. Portugal.

2. Instituto de Ciências Biomédicas Abel Salazar. Universidade do Porto. Porto. Portugal.

3. Serviço de Dermatologia. Centro Hospitalar de Lisboa Central. Lisboa. Portugal.

4. Serviço de Dermatologia. Hospital da Luz. Lisboa. Portugal.

5. Unidade de Psoríase. Hospital Cuf - Descobertas. Lisboa. Portugal.

6. Serviço de Dermatologia. Centro Hospitalar de Leiria. Leiria. Portugal.

7. Serviço de Dermatologia. Clinica Laser de Belém. Lisboa. Portugal.

8. Serviço de Dermatologia. Centro Hospitalar de S. João. Porto. Portugal.

9. Departamento de Farmacologia e Terapêutica. Faculdade de Medicina. Universidade do Porto. Porto. Portugal.

10. Consulta de Fototerapia. Serviço de Dermatologia. Hospital de Santo António dos Capuchos. Centro Hospitalar de Lisboa Central. Lisboa. Portugal.

11. Serviço de Dermatologia. Centro Hospitalar e Universitário de Coimbra. Coimbra. Portugal.

12. Unidade Curricular de Dermatologia. Escola de Ciências da Saúde. Universidade do Minho. Braga. Portugal.

13. Unidade de Dermatologia. Hospital dos Lusíadas. Lisboa. Portugal.

14. Centro de Ambulatório. Centro Hospitalar de Vila Nova de Gaia e Espinho. Vila Nova de Gaia. Portugal.

15. Unidade de Fototerapia. Serviço de Dermatologia. Centro Hospitalar de Vila Nova de Gaia e Espinho. Vila Nova de Gaia. Portugal.

16. Sociedade Portuguesa de Dermatologia e Venereologia. Lisboa. Portugal.

17. Serviço de Dermatologia. Centro Hospitalar do Porto. Porto. Portugal.

18. Colégio de Especialidade de Dermatologia. Lisboa. Portugal.

19. Serviço de Dermatologia. Centro Hospitalar Lisboa Norte. Lisboa. Portugal.

20. Unidade Curricular de Dermatologia. Faculdade de Medicina. Universidade de Lisboa. Lisboa. Portugal.

21. Unidade de Investigação em Dermatologia. Instituto de Medicina Molecular. Universidade de Lisboa. Lisboa. Portugal.

$\triangle$ Autor correspondente: Tiago Torres. torres.tiago@outlook.com

Recebido: 16 de agosto de 2016 - Aceite: 17 de agosto de 2016 | Copyright @ Ordem dos Médicos 2016 
of health care systems, as it has been observed in oncology and endocrinology setting. However, due to considerable differences between countries' health systems, there may be high variability in budget impact saving between countries.

Although developing a biosimilar with an efficacy and safety profile similar to the reference product can be challenging, due to the complex molecular structure and complicated manufacturing process, currently, there is a high regulatory bar for biosimilar products and their approval is a highly regulated procedure. EMA first developed guidelines for approval of biosimilars in $2005^{7}$ that were later updated and in 2013 a specific guideline for monoclonal antibodies was adopted. ${ }^{8}$ According to these guidelines, to demonstrate biosimilarity and gain regulatory approval for a biosimilar, EMA (and also other regulatory agencies, like FDA) require a pharmacokinetic/pharmacodynamics study in humans and at least one randomized clinical trial to demonstrate equivalent efficacy, immunogenicity and similar safety profile as compared to its reference product ${ }^{8}$. Nevertheless, the main safety issues concerning biosimilars are related to immunogenicity, hypersensitive reactions and an increased risk of other adverse effects.

There are several debatable considerations related to biosimilars, mainly extrapolation, interchangeability and automatic substitution, naming and traceability and longterm safety.

Extrapolation means that a clinical indication of a reference drug may be granted to the biosimilar without the requirement for clinical studies to support that indication. It is basically supported by the assumption that the two agents have similar molecular structure, mechanisms of action and equivalent clinical efficacy and safety. The possibility of gaining approval for all indications held by the reference product based on less extensive nonclinical data, and minimal clinical data in only a subset of indications is a main driver of biosimilar cost reduction. EMA allows extrapolation of indications, mentioning that efficacy and safety data for a biosimilar agent could be generalized from one indication to another 'if the reference product acts by the same mechanism in each disease state'. ${ }^{9}$

Untill this date, two biosimilars have been approved for treatment of psoriasis and psoriatic arthritis, CT-P13 (infliximab biosimilar - Remsima ${ }^{\mathrm{TM}}$, Celltron, Inc and Inflectra ${ }^{\mathrm{TM}}$, Hospira, Inc) and SB4 (etanercept biosimilar - Benapali ${ }^{\mathrm{TM}}$, Samsung Bioepis Co.), based in studies in rheumatoid arthritis (CT-P13 and SB4) and ankylosing spondylitis (CT-P13). ${ }^{10,11}$ The main issue raised by the concept of extrapolation of indications is in what specific inflammatory disease or diseases should a biosimilar agent be studied in order to provide adequate information for extrapolation of indications. In fact, although the therapeutic target (TNF- $\alpha$ ), is implicated in the pathophysiology of several immune-mediated diseases, their clinical manifestations are distinct, and their mechanisms of action, sites of action, pharmacokinetics, dose, concomitant medications, comorbidities, immunogenicity risk and safety profile may widely differ. Moreover, there is some serious and relevant debate on whether rheumatoid arthritis is the best model (most sensitive) to evaluate biosimilarity and to provide data for extrapolation, due to different dose regimen, concomitant use of methotrexate and different pathogenesis. ${ }^{12}$ However, many of the concerns raised regarding extrapolation may be hypothetical, and likely not problematic in the long term. In fact, there is increasing evidence that the use of Infliximab biosimilar (CT-P13), approved for all the originator's indications based on clinical trials conducted in patients with rheumatoid arthritis and ankylosing spondylitis, is also effective and safe in inflammatory bowel disease. ${ }^{13-15}$

Nevertheless, dermatologists will probably be more confident and less reluctant using biosimilars that have been previously studied in psoriasis patients, and currently, several biosimilars of adalimumab and etanercept are being evaluated in psoriasis patients. ${ }^{5}$

Regarding switching a reference product by a biosimilar, or vice-versa, there are several relevant considerations for clinical practice. Drug switching refers to the transitioning from one biologic agent to another (reference to biosimilar and vice-versa); automatic substitution refers to replacement of one biologic agent with another by the pharmacist without the approval or knowledge of the prescribing physician; interchangeability or the condition of an 'interchangeable biological' has been defined by the FDA as a product that "in addition to meeting the biosimilarity standard, is expected to produce the same clinical result as the reference product in any given patient, and for a product that is given to a patient more than once, the risk in terms of safety and effectiveness of alternating or switching between the interchangeable and the reference product is not greater than the risk of using the reference product without alternating or switching'. ${ }^{16}$ In order to considered an interchangeable biological, the agent must meet specific criteria that are currently under consideration by the FDA, for instance, it may be necessary to previously perform crossover and repeated switching studies. Once a biosimilar has proved to be interchangeable, a pharmacist might replace the reference product, without the intervention of the physician who prescribed the reference product, in other words, automatic substitution. However, EMA has no addressed the issues of interchangeability, switchability and automatic substitution of biosimilar and reference products, leaving the corresponding decisions in the hands of the health authorities of each member state of the European Union. ${ }^{17}$

There is not clear evidence supporting switching and interchangeability. Currently, there are some studies accessing real-world data about switching, for example the Norwegian NOR-SWITCH study, that evaluates, for a period of 12 months, maintenance of efficacy as well as safety following switching from reference to biosimilar infliximab. However, it should not be forgotten that this is a 'one switch study' that may only demonstrate no loss of efficacy nor increase risk for this biosimilar in particular and for just one switch. Switching, or even interchangeability will only be accepted with robust evidence, probably through multiple 
switching studies conducted during the development of the biosimilar. As an example, the etanercept biosimilar GP2015 is being studied in a phase III crossover trial, with more than one switch, in psoriasis. ${ }^{18}$

Due to the abbreviated clinical development programme of biosimilar agents, which is less able to identify small safety risks as compared with the development of reference products, post-marketing pharmacovigilance is of critical importance for assessment of long-term safety of biosimilars. EMA has designed a complete post-marketing pharmacovigilance program for biosimilars which includes a post-marketing safety study as well as the implementation of a risk management plan, that included spontaneous reports of potential side effects related to use of a biosimilar after these are reported by patients or healthcare professionals, creation of periodic safety update reports and promotion of post-authorization safety studies. ${ }^{19}$

Another important aspect concerns naming of biosimilars as it may significantly affect both affect traceability and pharmacovigilance. There is no established international standardized system of nomenclature for biosimilars, which is currently determined on a national level. EMA advises that commercial name, appearance and packing should differ. ${ }^{17}$

In February 2016 the Portuguese National Authority of Medicines and Health Products (INFARMED, IP) released a recommendation document about the use of biosimilars. In this document, it is clearly recommended the use of biosimilars as it is associated with reduced therapy-related costs and increase patients' access to biological therapies. Moreover, it is recommended that therapeutic agents with approved biosimilars should be the first choice of treatment. For naïve patients, it is recommended as first option the use of biosimilars (if it is more economic than the reference agent) at all the approved clinical indications the reference product has, thus showing no concerns regarding the extrapolation of indications. The importance of pharmacovigilance and traceability is highlighted with recommendations regarding these aspects. Finally, no clear position is stated regarding switching between reference and biosimilar agents. Some concerns are expressed regarding safety issues, specifically immunogenicity, and it is recommended that any decision should be taken cautiously always involving the clinicians that are responsible for patients' care. ${ }^{20}$

\section{Portuguese position on the use of biosimilars in psoriasis}

- Biosimilars are welcomed in the treatment of psoriasis and psoriatic arthritis if they are able to reduce medical costs and increase access to biologic therapy, improving patient's care and providing saving and efficiency for health care systems, therefore releasing resources for others important aspects of health care.

- In patients' best interest, the development of biosimilars must be critically evaluated. Medical and immunological considerations, including high-quality evidence of bioequivalence, quality, efficacy and safety of each developed biosimilar should always take priority over any economic or financial benefit.

- Many of the concerns raised regarding extrapolation may in the future prove to have no practical impact. However, since several biosimilars are being evaluated in psoriasis patients, these agents should be chosen to treat psoriasis patients instead of biosimilars studied in other conditions.

- There is no evidence to support switching between a reference biologic agent and a biosimilar and vice-versa, so this should not be recommended.

- Any decision to substitute a biosimilar product should only be made by the prescribing physician and automatic substitution is strongly objected. Moreover, patients should be kept informed about their treatment agent, and should not be transitioned for other agent without their knowledge and informed consent.

- Biosimilars should be subjected to the same standards of pharmacovigilance as do the reference biological agents. Post-marketing surveillance, mainly through national registers, is crucial to permanently assess safety and increase confidence in the use of biosimilars.

- In the absence of established international standardized system of nomenclature for biosimilars, careful biosimilar identification and recording (including the brand name and batch number) is of utmost importance for safety reasons and for securing traceability.

- Biosimilars should not prevent or delay access to therapeutic innovation, and physicians must retain full authority concerning the decision of which therapeutic agent is selected to treat their patients.

- These opinions may change with time. Daily clinical experience and new data will be of critical importance.

\section{CONFLICTS OF INTEREST}

Tiago Torres was a speaker, member of the Advisory Board, participated in observational research/clinical trials at and/or received research support from: Abbvie, Amgen, Boehringer Ingelheim, Janssen-Cilag, Leo-Pharma, LillyEli, Merck-Serono, Merck Sharp \& Dohme, Novartis, Pfizer;

Ana Ferreira was a speaker, member of the Advisory Board and participated in observational research at: Abbvie, Janssen-Cilag, Leo-Pharma, Novartis, Pfizer;

Paulo Ferreira was a speaker, member of the Advisory Board, participated in observational research/clinical trials at and/or received research support from: Abbvie; JanssenCilag; Leo-Pharma; Lilly- Eli; Novartis; Pfizer;

Martinha Henriques was a speaker and/or member of the Advisory Board at: Abbvie, Janssen, Pfizer, LeoPharma;

Luiz Leite was a speaker and/or member of the Advisory Board at: Abbvie, Janssen, Pfizer;

Gabriela Marques Pinto was a speaker, member of the Advisory Board, participated in observational research/ clinical trials at and/or received research support from: Abbvie, Janssen-Cilag, Leo-Pharma, Lilly-Eli, Merck- 
Serono, Merck Sharp \& Dohme, Novartis, Pfizer;

Artur Sousa Bastos was a speaker and/or member of

the Advisory Board at: Abbvie, Janssen, Pfizer;

Rui Tavares Bello was a speaker, member of the

Advisory Board, participated in observational research/ clinical trials at and/or received research support from: Abbvie, Fujisawa, Janssen, Leo-Pharma, UCB, Merck Sharp \& Dohme, Galderma, Medinfar, Novartis, Pfizer;

Paulo Varela was a speaker, member of the Advisory Board, participated in observational research/clinical trials at and/or received research and training support from: Abbvie, Janssen, Galderma, Leo-Pharma, Lilly-Eli, Serono,

\section{REFERENCES}

1. Torres T, Velho GC, Sanches M, Selores M. Psoriasis in the era of biologics. Acta Med Port. 2010;23:493-8.

2. Marques Pinto G, Filipe P. Guidelines for high-quality use of biologic therapies in adults with plaque psoriasis. Acta Med Port. 2012;25:12541.

3. Araújo F, Gonçalves J, Fonseca JE. Biosimilar DMARDs: what does the future hold? Drugs. 2016;76:629-37.

4. European Medicines Agency. Guideline on similar biological medicinal products containing biotechnology-derived proteins as active substance: non-clinical and clinical issues. 2014. [consulted 2016 Jul 18.]. Available from: http://www.ema.europa.eu/docs/en_GB/document_library/ Scientific guideline/2015/01/WC500180219.pdf.

5. Dörner T, Kay J. Biosimilars in rheumatology: current perspectives and lessons learnt. Nat Rev Rheumatol. 2015;11:713-24.

6. Torres T, Filipe P, Selores M. Impact of biosimilars in psoriasis treatment. Acta Med Port. 2013;26:646-48.

7. European Medicines Agency. EMEA/CHMP/BMWP/42832/2005 Rev1: Guideline on similar biological medicinal products containing biotechnology-derived proteins as active substance: non-clinical and clinical issues; 18 December 2014. [consulted 2016 Jul 18]. Available from: http://www.ema.europa.eu/docs/en_GB/document_library/ Scientific_guideline/2015/01/WC500180219.pdf.

8. European Medicines Agency. EMA/CHMP/BMWP/403543/2010: Guideline on similar biological medicinal products containing monoclonal antibodies-non-clinical and clinical issues. [consulted 2016 Jul 18]. Available from: http://www.ema.europa.eu/docs/en_GB/document_ library/Scientific_guideline/2012/06/WC500128686.pdf.

9. Committee for Medicinal Products for Human Use. Guideline on similar biological medicinal products containing biotechnology-derived proteins as active substance: nonclinical and clinical issues. European Medicines Agency [online]. [consulted 2016 Jul 18]. Available from: http://www.ema. europa.eu/docs/en_GB/document_library/Scientific_guideline/2015/01/ WC500180219.pdf.

10. European Medicines Agency. European Medicines Agency recommends approval of first two monoclonal-antibody biosimilars. 2013. [consulted 2016 Jul 18]. Available from: http://www.ema.europa.eu/ema/index. jsp?curl=pages/news_and_events/news/2013/06/news_detail_001837. jsp\&mid=WCOb01ac058004d5c1.
Novartis, Pfizer;

Manuela Selores was a speaker, member of the Advisory Board, participated in observational research/clinical trials at: Astellas, Galderma, GlaxoSmithKline, Janssen-Cilag, Merck-Serono, Novartis, Pfizer;

Paulo Filipe: was a speaker, member of the Advisory Board, participated in observational research/clinical trials at and/or received research support from: Abbvie, Amgen, Boehringer Ingelheim, Janssen-Cilag, Leo-Pharma, LillyEli, Merck-Serono, Merck Sharp \& Dohme, Novartis, Pfizer; Sofia Magina, Hugo Oliveira and António Massa declare that they have no conflicts of interest towards this paper.

11. European Medicines Agency. Summary of opinion (initial authorisation) Benepali. [consulted 2016 Jul 18]. Available from: http://www.ema. europa.eu/docs/en_GB/document_library/Summary_of_opinion_-_ Initial_authorisation/human/004007/WC500196736.pdf.

12. Lee $\bar{H}$. Is extrapolation of the safety and efficacy data in one indication to another appropriate for biosimilars? AAPS J. 2014;16:22-6.

13. Farkas K, Rutka M, Bálint A, Nagy F, Bor R, Milassin Á, et al. Efficacy of the new infliximab biosimilar CT-P13 induction therapy in Crohn's disease and ulcerative colitis - experiences from a single center. Expert Opin Biol Ther. 2015;15:1257-62.

14. Jung YS, Park DI, Kim YH, Lee JH, Seo PJ, Cheon JH, et al. Efficacy and safety of CT-P13, a biosimilar of infliximab, in patients with inflammatory bowel disease: A retrospective multicenter study. J Gastroenterol Hepatol. 2015;30:1705-12.

15. Gecse KB, Lovász BD, Farkas K, Banai J, Bene L, Gasztonyi B, et al. Efficacy and safety of the biosimilar infliximab CT-P13 treatment in inflammatory bowel diseases: a prospective, multicentre, nationwide cohort. J Crohns Colitis. 2016;10:133-40.

16. US Food and Drug Administration. Information for Consumers (Biosimilars). 2015. [consulted 2016 Jul 19]. Available from: http://www.fda.gov/Drugs/DevelopmentApprovalProcess/ HowDrugsareDevelopedandApproved/ApprovalApplications/ TherapeuticBiologicApplications/Biosimilars/ucm 241718.htm.

17. European Commission. What you need to know about Biosimilar Medicinal Products-Consensus Information Paper 2013. [consulted 2016 Jul 15]. Available from: http://ec.europa.eu/DocsRoom/ documents/8242/attachments/1/translations/en/renditions/native.

18. Sandoz. Study to demonstrate equivalent efficacy and to compare safety of biosimilar Etanercept (GP2015) and Enbrel (EGALITY). 2015. [consulted 2016 Jul 19]. Available from: https://www.clinicaltrials.gov/ ct2/show/ NCT01891864

19. Casadevall N, Edwards IR, Felix T, Graze PR, Litten JB, Strober BE, et al. Pharmacovigilance and biosimilars: considerations, needs and challenges. Expert Opin Biol Ther. 2013;13:1039-47.

20. Comissão Nacional de Farmácia Terapêutica. Orientações. [consulted 2016 Jul 18]. Available from: http://www.infarmed.pt/portal/page/portal/ CTE/Comissao_Nacional_de_Farmacia_Terapeutica/FNM_ANEXOS/ Orienta\%E7\%F5es_CNFT_Completa_Final.pdf 